\title{
O PAPEL DA TRADUÇÃO RENASCENTISTA NA REELABORAÇÃO LITERÁRIA DAS LÍNGUAS NEOLATINAS ${ }^{1}$
}

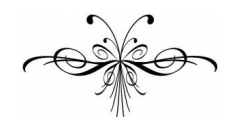

\author{
LEILA TERESINHA MARASCHIN
}

\begin{abstract}
Resumo: Este artigo apresenta algumas considerações sobre o papel da tradução renascentista na reelaboração das línguas neolatinas, focalizando especialmente a influência da elocutio retórica no novo modo de traduzir que aprimora suas literaturas.
\end{abstract}

Palavras-chave: Tradução renascentista. Elocutio. Escrita literária. Línguas neolatinas.

\begin{abstract}
This article presents some considerations about the role of renaissance translation in the re-elaboration of the Romance languages, focusing particularly on the influence of Rhetoric's elocutio to a new way of translating that enriches the literatures in those languages.
\end{abstract}

Keywords: Renaissance Translation. Elocutio. Literary Writing. Romance languages.

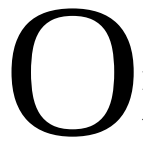

Renascimento é um momento especial no desenvolvimento de muitas línguas vulgares europeias, em especial daquelas que mais tarde iriam adquirir o status de nacionais. No âmbito da história da tradução, o aspecto mais relevante dessa renascença é o novo modo de traduzir, que, junto ao aumento do volume e variedade de obras traduzidas, contribui para a reelaboração de muitos vernáculos literários. Nessa época, com a divulgação do grego clássico e do método filológico bizantino, a partir dos humanistas, foram realizadas diversas traduções inéditas e retraduções de obras antigas. Começaram a se ampliar, também, as reflexões sobre como traduzir. Através do conhecimento filológico, que facilitou a recuperação dos textos clássicos, e da retórica centrada na elocutio, a tradução desenvolveu-se como estética literária, tendo conquistado, entre os séculos XV e XVI, um lugar de destaque em diversas línguas modernas (FURLAN, 2002).

1 Este artigo é parte da minha tese de doutorado, “Antologia sobre a dignificação do vernáculo no Renascimento: A tradução como partícipe no processo de estabelecimento das línguas neolatinas”, realizada no Programa de Pós-Graduação em Estudos da Tradução da Universidade Federal de Santa Catarina, sob a orientação do Prof. Dr. Mauri Furlan. Os textos renascentistas aqui citados, com sua respectiva tradução, constituem o corpus da referida tese. 
Diante de novos desafios e movidos por novos ideais, muitos letrados empenharam-se para dar autonomia à língua de seu grupo, promovendo, com isso, a elevação de muitas variedades vernaculares à categoria de língua culta. A partir da primeira metade do século XVI, começam a aflorar, cada vez mais, textos cujos conteúdos evidenciam o desejo de afirmação dos modelos literários das novas línguas europeias, cujos autores e obras tornar-se-ão os novos clássicos (MICÓ, 2004).

Entre as questões linguísticas que emergem no novo momento histórico, como a relação entre as línguas clássicas e as vulgares, os usos falados e escritos, os modelos dignos de imitar, a história e a crítica da literatura, a necessidade de normalização dos vernáculos e a autoridade política para instituí-los, são frequentes também as referências ao modo de traduzir. Ampliam-se os debates acerca de questões específicas sobre a atividade tradutória, com base nos fenômenos observados em diversas línguas, incluindo as modernas.

Nos primeiros tempos do Humanismo, a preocupação maior dos letrados havia sido com a restauração do latim clássico, como forma de vincular o pensamento da época aos valores da Antiguidade, afastando-o do domínio da escolástica medieval. No entanto, o uso deste latim recuperado ficou restrito a poucos, o que dificultava a divulgação da cultura clássica. Além disso, o uso dos vernáculos impunha-se cada vez mais, sobretudo com a expansão da imprensa e o aumento do número de leitores provenientes das classes em ascensão econômica, mas sem o grau de erudição exigido para a compreensão da língua de Cícero.

A partir do embate entre os que defendiam a excelência das línguas clássicas e os que lutavam pelo emprego das línguas vulgares, iniciou-se um movimento rumo à afirmação do vernáculo. Na Itália, em 1525, Pietro Bembo publica o tratado Prose della volgar lingua, defendendo as potencialidades do vernáculo florentino, o qual considera uma língua tão literária quanto o latim (BEMBO, 1966). Também em outras comunidades neolatinas cresce, nesta época, o número de eruditos que concentram seus esforços na valorização, no aprimoramento estético e na exaltação da língua local.

Embora o uso de muitas das línguas vulgares já estivesse bastante difundido, não raro pesava sobre elas denominações discriminatórias como "bárbaras”, “corrompidas” e "incultas”, o que aumentava a necessidade de serem habilitadas conforme a tradição literária greco-latina. Esta habilitação ocorre através de duas ações básicas, promovidas e executadas pelos letrados renascentistas: o enriquecimento e a exaltação, ambos representados pelo que Joachim Du Bellay chamou, no caso do francês, de illustration, em que se buscavam elementos culturais para confirmar as qualidades nobres do vernáculo (HIGHET, 1954, p. 366).

O enriquecimento refere-se, primeiramente, ao léxico, conforme os requisitos das palavras na concepção gramático-retórica, em que as línguas eram divididas em "ricas” e “pobres”. As línguas clássicas eram ricas por possuírem grande quantidade de palavras (copia et abundantia); as línguas vernaculares, ao contrário, eram todas consideradas desprovidas de recursos, sobretudo em relação aos vocábulos literários. Além da abundância de palavras, havia outros aspectos que também eram considerados relevantes nas línguas ricas, como o número (duração do som na pronúncia das vogais, responsável pela formação dos pés métricos), as flexões verbo-nominais e a liberdade na colocação dos termos, o que, na 
versificação clássica, favorecia a composição equilibrada das sentenças e a sua musicalidade.

A respeito da "riqueza", ou posse do maior número de recursos, entre as línguas clássicas, que no século XVI serviam de modelo para as vulgares, havia uma hierarquia, em que o grego era colocado no topo, seguido pelo latim e, por último, o hebraico. Entre os vernáculos, começou a surgir uma nova hierarquia, em que os letrados de cada país colocavam a sua língua na posição mais elevada, ora procurando afinidades com as línguas clássicas, ora inventando-lhe origens nobres (BARROS, 1540; GELLI, 1551). Expressar fielmente os textos clássicos na língua local fazia com que esta adquirisse valor artístico, afastando a visão de que ela seria uma simples forma corrompida do latim. Por isso, a tradução renascentista, cujo volume e diversidade de obras se amplia, assume um papel importante na elevação do status literário das línguas modernas.

No presente trabalho, são abordadas algumas questões ligadas à atividade tradutória renascentista como parte integrante das práticas que ajudaram a consolidar o grupo das línguas neolatinas cuja reelaboração literária foi embasada na retórica clássica, e que é composto pelo espanhol, francês, italiano e português.

\section{A tradução artística na reelaboração literária das línguas neolatinas}

Da família românica, ou neolatina, composta hoje por mais de vinte línguas, destacam-se, na época renascentista, o francês, o italiano, o espanhol e o português. Estas quatro línguas são as que começaram, entre os séculos XV e XVI, a ter reconhecimento na produção literária e no uso escrito em geral, sob influência dos princípios gramático-retóricos da Antiguidade clássica. Naquele momento histórico, por questões de cunho político e/ou de interesse literário, estas línguas ganharam maior visibilidade e, por conseguinte, apresentam maior número de dados a respeito da sua emancipação cultural, bem como da importância do papel que o novo modo de traduzir exerceu na sua formação culta.

Até a época renascentista, as línguas neolatinas situavam-se todas abaixo das chamadas línguas ricas e, para se tornarem autônomas, necessitavam, sobretudo, de novas palavras. As línguas clássicas forneciam-lhes elementos para a literatura, mas não bastavam para que um vernáculo pudesse distinguir-se e rivalizar com outro(s). Para isso, os letrados precisavam buscar aquelas palavras que estavam em uso no seu próprio território, ou tomadas de outros povos, ou ainda criar termos a partir da derivação do latim. Na etapa inicial, eles propunham várias maneiras de melhorar a condição da língua local, tais como acréscimo de neologismos, arcaísmos e regionalismos vocabulares, reconhecimento de misturas linguísticas, normalização gramatical, harmonização sonora e adequação gráfica.

Para a inserção de neologismos técnicos e, sobretudo, literários, as novas línguas contavam com a contribuição da tradução das obras greco-latinas. Em seguida, quando cada um dos vernáculos já se encontrava em condições de competir, tanto com o latim quanto com as línguas vulgares das outras comunidades, então ocorria a sua exaltação, momento em que os letrados publicam elogios, incitando os demais usuários para que escrevam obras na sua própria língua e aperfeiçoem-na. A participação da tradução continua a ocorrer, desta vez como uma prova da aptidão da nova língua, pelo fato de que, depois de enriquecida, ao conseguir expressar uma obra valorosa tão bem quanto na língua em que havia sido produzida, poderia obter o mesmo esplendor literário desta. 
Aos poucos, começa a diminuir o confronto entre o mérito atribuído às línguas clássicas e às vulgares. Mesmo porque, no trabalho de enriquecer e exaltar sua língua, os defensores do vernáculo acabaram sendo beneficiados pelos classicistas. Pois, para demonstrar a dedicação à própria língua, um dos exemplos seguidos era imitar a atitude dos bons autores da Antiguidade, cujas obras se lhes haviam tornado acessíveis, na maior parte, graças à recuperação feita pelos filólogos humanistas. Dentre os romanos, os renascentistas seguem, em especial, o exemplo de Cícero, que havia acrescentado ao latim vários elementos do grego, tornando assim sua língua apta para expressar os textos escritos na língua grega. Os gregos e os romanos são citados como bons exemplos por terem valorizado as suas línguas, produzindo grandes obras, cada um na sua própria: “Os gregos não escreveram em egípcio, os latinos não escreveram em árabe”2 (PELETIER, 1555; MARASCHIN, 2015, p. 407); “[...] quase nunca se encontrou grego que escrevesse coisa sua em latim; nem houve romano que se valesse mais do grego do que de sua própria língua”3. (MORALES, 1586; MARASCHIN, 2015, p. 318)

$\mathrm{Na}$ exaltação à língua local, o letrado renascentista, ao tentar fazê-la rivalizar com outro(s) vernáculo(s), às vezes usava o parentesco com as línguas clássicas como elemento de distinção e prestígio. Essa proximidade, no entanto, não significava a simples aceitação de termos greco-latinos, como ocorria nas versões romanceadas feitas durante a Idade Média, e também em algumas traduções do grego ao latim, conforme as observações feitas pelo humanista Leonardo Bruni (1420-6; FURLAN, 2011, p. 21-2) a respeito de palavras traduzidas de maneira equivocada porque não havia sido dada atenção ao verdadeiro sentido da sentença, nem ao contexto da recepçãoobservações essas que, entre outras, constituem a especificidade da tradução renascentista, comprometida com os valores artísticos da composição. Entre os renascentistas, para o enriquecimento do vernáculo através da tradução dos clássicos, não se dispensava o trabalho lexicográfico do tradutor retórico, que recriava as palavras, mantendo a raiz original, mas conformando-as com o sistema da língua local. Era preciso, portanto, acrescentar "as cores” ao vernáculo, como recomenda Peletier (1555; MARASCHIN, 2015, p. 409), na sua Art poétique: "Uma palavra bem derivada do latim terá muita graça ao dar-lhe uma tintura francesa." 4

O processo de ampliação lexical dos vernáculos, que havia iniciado na Idade Média, tornou-se ainda mais vigoroso no Renascimento, por causa do cuidado com a adequação dos elementos às línguas receptoras durante a tradução, em especial de obras literárias produzidas na Antiguidade clássica. A relação entre as línguas tidas como ricas e pobres, que era vertical, agora tende a se horizontalizar; e o traduzir, então, distingue-se do simples vulgarizar ${ }^{5}$ (FOLENA, 1994), porque agora os clássicos já podem ser expressos em vernáculo com todos os seus valores artísticos. Esta distinção é própria da tradução renascentista, cuja principal característica é a influência da retórica elocutiva.

\footnotetext{
2 “Les grecs n’ont pas écrit en égyptien: les latins n’ont pas écrit en arabique.”

3 “[...] nunca cuasi se halló griego que escribiese en latín cosa suya; ni hubo Romano que se preciase mas del griego para encomendar a él su nombre, y su fama, que de su propia lengua.”

4 "Un mot bien déduit du Latin aura bonne grâce, en lui donnant la teinture française."

5 Na Idade Média, verter/adaptar textos de uma língua a outra com objetivo didático-divulgativo.
} 
Segundo Furlan (2002), a tradução, no período compreendido entre os séculos XV e XVI, destaca-se pela convergência de pensamento dos tradutores, que, ao escreverem sobre a própria atividade, revelam uma concepção de linguagem com base na retórica clássica, cujo sistema, elaborado pelos gregos antigos, havia sido retomado pelos humanistas. Quando os romanos começaram a usar o sistema grego para estudar o latim, perceberam que havia semelhanças e diferenças entre as duas línguas, o que os levou a criar a noção de proprietates linguae, as características que fazem com que uma língua se diferencie de outra. Mais tarde, com a expansão do império romano, o latim foi tomado como modelo para o aperfeiçoamento das línguas vernáculas ocidentais e as categorias gramáticoretóricas, com sua terminologia, foram então adotadas para a reelaboração das literaturas e das regras gramaticais de algumas dessas línguas.

Furlan (2002), ao analisar textos produzidos nos séculos XV e XVI que tratam acerca da tradução, e levando em conta as questões específicas daquele momento histórico, defende a composição de uma teoria da tradução própria do Renascimento. Através das principais fontes primárias que trazem reflexões sobre a atividade tradutória, o autor demonstra como a concepção retórica da linguagem da época, em que predomina a elocutio, reflete-se na produção literária e, por extensão, na tradução, constituindo uma nova teoria, a qual denomina "retórica elocutiva da tradução renascentista". Entre os aspectos principais dessa teoria, destaca-se a "habilidade poética" do tradutor, o que caracteriza a tradução renascentista como renovadora da língua de chegada.

Nesse sentido, a retórica renascentista desempenha um papel fundamental no desenvolvimento literário daqueles vernáculos que começam a ganhar notoriedade a partir do século XV e, principalmente, no século XVI, como é o caso das quatro línguas neolatinas mencionadas em nosso estudo. A tradução artística aprimora as novas línguas ao atentar para a recuperação não apenas do sentido, mas também de todos os aspectos formais do texto de partida, em que são considerados os requisitos básicos da arte retórica, como a clareza, a harmonia e a ornamentação adequada. Esse novo modo de traduzir visa a uma construção textual que se atém à totalidade dos valores das línguas envolvidas no processo tradutório. E são esses valores que vão favorecer, no Renascimento, a reelaboração literária de muitas línguas europeias modernas.

A especificidade da tradução renascentista tem suas origens na releitura da Antiguidade clássica, cujo sistema de ensino, retomado pelos filólogos humanistas, amplia o conhecimento ao implantar os estudos de grego no ocidente e trazer as fontes originais da arte retórica (KRISTELLER, 1993). Além disso, é preciso considerar a presença da tradição clássica na formação do letrado, em especial quanto ao domínio disciplinar da gramática e da retórica. O ponto de partida destes saberes, entre os antigos, era a concepção de que as ideias preexistiam às palavras, só se manifestando quando colocadas em um signo exterior. A linguagem era, para eles, entendida primordialmente como "expressão do pensamento por meio das palavras” (LAUSBERG, 1972, p. 116). Por isso, para uma comunicação e expressão eficazes, o usuário da língua culta precisava ter o domínio das suas formas, adquirido através do estudo e do exercício sistemático da gramática e da retórica. 
No Renascimento, tanto a gramática quanto a retórica apresentavam-se em duas modalidades. A primeira em forma de disciplinas escolares, mais ou menos conforme a estudavam os gregos e os romanos; e a segunda como modo de conceber a linguagem. Nesta segunda modalidade é que ocorrem as mudanças mais significativas para a época renascentista, quando as letras vernáculas começam a ser tratadas sob essa concepção e a retórica elocutiva predomina na prática literária, incluindo-se a tradução. (FURLAN, 2002)

Partindo da palavra, que era o material básico do trabalho gramáticoretórico, primeiro como unidade (uerba singula) e depois como agrupamento (uerba coniuncta), o estudante adquiria competência na língua. A gramática fornecia-lhe os aspectos básicos que possibilitavam a comunicação, e a retórica, depois, ensinava-o a tornar essa comunicação efetiva. Ao selecionar as palavras que iriam (re)compor o texto traduzido, o tradutor devia levar em conta as suas características, dadas pela gramática, como a propriedade, a adequação e a compreensibilidade. O domínio desses requisitos era imprescindível para a produção textual, tanto nas criações literárias e traduções, quanto na redação de cartas, tratados ou outros escritos, e também nas conversações entre os grupos de elite, conforme expõe Valdés (1535), no seu Diálogo de la lengua.

Dentre as partes da retórica clássica ${ }^{6}$, a elocutio é a que mais influencia na reelaboração das línguas e das literaturas no ocidente. De acordo com Furlan (2002), ela se torna, durante o Renascimento, o fator de maior relevância da teoria retórica geral da linguagem, porque deixa de ser apenas um dos elementos do discurso no sistema da retórica e passa a constituir uma operação abrangente de todo o discurso literário que envolve textualização artística, no qual a tradução é inserida. A tradução elocutiva pressupunha o domínio da gramática, adquirido pelo exercício com a palavra, tanto isoladamente quanto na construção frasal. O tradutor, conhecendo as propriedades das palavras, devia combinar o conteúdo com a estética textual, de modo a preservar todos os valores do texto de partida na recriação do estilo.

A ornamentação na tradução renascentista consistia em expressar o pensamento do autor sem prejudicar o valor estético da obra. Por isso o tradutor escolhia as palavras adequadamente, procurando, ao recompor o texto, observar detalhes como a estrutura métrica e a sonoridade. Esse requisito, por priorizar a língua receptora, é de grande importância para o aprimoramento das línguas vernáculas aqui referidas, visto que a tradução, ao ser tratada como uma obra de arte, promoveu suas literaturas.

Através dos exercícios de desconstrução e reconstrução do texto, do enfrentamento de problemas e busca de soluções, a atividade tradutória desenvolveu-se e tornou-se, para os renascentistas, também objeto de análise, ao lado de outras questões relativas aos problemas linguísticos e literários. Para eles, a cultura do traduzir contempla, com a máxima atenção, a língua de chegada, sem no entanto abandonar a língua de partida. Pelo contrário, o fato de não se deixar perceber a língua do original no texto traduzido poderia ser visto como um sinal de tradução bem sucedida e de abundância da língua receptora, e não de menosprezo da fonte, em especial quando se tratava de um texto clássico grego ou latino.

6 Respectivamente: 1. Inuentio (Exordium, Narratio, Argumentatio e Peroratio); 2. Dispositio; 3. Elocutio (Latinitas, Perspicuitas, Ornatus, Aptum e Vitia); 4. Memoria e 5. Pronuntiatio. 


\section{LITERÁRIA DAS LÍNGUAS NEOLATINAS}

Desse modo, a atividade tradutória, pautada pela habilidade artística, refletiu-se na produção literária local, pois, uma obra considerada bem escrita, ao ser traduzida da forma mais abrangente possível, criava uma exigência na língua de destino, que deveria oferecer as mesmas possibilidades para que essa obra se expressasse inteiramente, isto é, com todos os seus valores estéticos. Assim, o papel ou função da tradução, que sempre esteve na base da constituição das línguas e literaturas da Europa ocidental, desde os romanos antigos, passando pelas comunidades medievais, assume, no Renascimento, "fundamental importância" (BASSNETT, 2005).

Nesse período, além de exercício de gramática e retórica, propagação da fé e conhecimento das ciências em vernáculo, acrescenta-se à atividade tradutória um papel novo, que consiste na compreensão de todos os elementos do texto de partida (sentido e forma; contexto, modelos, gêneros, normas) e reconstrução da obra respeitando todas as propriedades da língua receptora. Esse papel artístico, ou "elocutivo", constitui a especificidade da tradução renascentista e está relacionado à concepção retórica da linguagem, a partir da qual são reelaboradas as línguas vernáculas e suas literaturas. As novas línguas, cada vez mais em expansão, necessitavam de aprimoramento estético, para que nelas se pudesse, além de traduzir conforme os critérios da época, também compor obras para formar os seus cânones literários. Os renascentistas enfatizavam, como observa Furlan (2002, p. 335), a exigência de uma "boa textualização e literariedade” na língua de chegada, procurando manter os valores do original, mas recriando a oratio (ou estilo e ritmo). A tarefa de traduzir, tanto quanto a de compor, passa a exigir conhecimento de todos os meios expressivos que permitam a construção de um texto esteticamente elevado, em que se destacam a escolha criteriosa do léxico, a organização sintática e, principalmente, a sonoridade.

Entre os séculos XV e XVI, a tradução e o tradutor se definem, porque a obra traduzida adquire valor de obra de arte e muda também o status do tradutor. A atividade tradutória passa então a ser considerada árdua, difícil e, quando bem executada, louvável, pelo talento artístico do tradutor, ou pelo benefício social que o seu trabalho proporciona. Segundo Burke (2010, p.180), a referência à difficultà (dificuldade), entre os renascentistas italianos, era usada justamente para ressaltar as qualidades do artista, que, ao conseguir superá-la, demonstrava sua habilidade. Daí pode-se depreender que, também para o tradutor, como artista da palavra, essa habilidade torna-se um requisito importante, uma vez que a tradução passa a ter valor estético.

Para chegarem ao patamar das línguas cultas, as línguas vulgares neolatinas aqui citadas tiveram antes de ser cuidadosamente reelaboradas pelos letrados, os quais, concebendo a tradução como uma arte, empenharam-se no desenvolvimento e na promoção do seu vernáculo. A tradução torna-se uma atividade relevante, e o tradutor, nessa época, assume uma grande responsabilidade perante a comunidade em que está inserido, pois a aptidão da língua moderna precisa confirmar que seus valores expressivos são equiparáveis aos das línguas clássicas e, ao mesmo tempo, que constituem elementos próprios e capazes de torná-la autônoma. 
A língua para a qual os renascentistas traduziam tinha de ser comum e acessível aos novos leitores, mas, por outro lado, diferente daquela usada nas várias situações de comunicação quotidiana, uma vez que essa não estaria apta para expressar integralmente o que os filósofos e/ou os poetas antigos haviam escrito em grego e latim, as línguas ditas "perfeitas” pelos humanistas. Nos seus aspectos formais e estilísticos, as línguas neolatinas eram consideradas ainda incompletas, uma vez que estavam "vivas” e sujeitas a constantes mudanças (GELLI, 1551). No léxico, para alcançarem a abundância das línguas denominadas ricas, muitas palavras precisavam ser criadas, outras recriadas e/ou legitimadas. Na sintaxe, sem desinências casuais, a organização da sentença requeria o domínio de outros recursos, como as preposições e a ordem direta. A pronúncia apresentava diversidades e a representação gráfica dos sons tinha de ser adequada.

As línguas clássicas haviam sido habilmente elaboradas pelos literatos antigos, enquanto os vernáculos tiveram um tempo de emprego literário muito menor. Por isso, a tradução, no Renascimento, além de transmissão de conhecimentos e expressão de valores artístico-literários dos antigos clássicos, torna-se também uma atividade visada pelos interessados no aprimoramento estético da própria língua. Sob a influência da arte retórica, cujos princípios regem o "bom” emprego da língua, o modo de traduzir passa a exigir grande "artifício" (engenho e juízo). Quanto maior a complexidade formal da língua-fonte, maior a tendência de os tradutores tentarem aproximar a língua de destino a ela, aproximação esta que, no caso dos vernáculos no Renascimento, era necessária para que se pudesse expressar o conteúdo dos textos clássicos com uma forma artística equivalente à da composição do texto de partida. Isso, porém, gerava problemas quanto às escolhas tradutórias, em especial com relação a ter de optar pelo sentido ou pela forma. É dentro dessa problemática que Valdés (1535; MARASCHIN, 2015) considera difícil traduzir do latim ao castelhano sem ter de alterar ou o sentido ou a letra:

[...] se alguém traduz aquele Idne estis auctores mihi? de Terêncio não querendo afastar-se da letra, terá de dizer "Disto sois autores para mim?” e assim não se entenderá o que o poeta quis dizer, porém, se, escrevendo de sua cabeça, quiser dizer aquela mesma sentença dirá: “Isto aconselhais a mim?”, e é o mesmo que sentiu o poeta, embora se diga por outras palavras. E da mesma maneira, se outro quiser por em romance aquele mesmo $O$ factum bene, beasti me, de Terêncio, diz: “Oh, como está bem feito! Tornaste-me bem aventurado”, não falará o castelhano próprio, nem exprimirá tão bem o que o poeta quis dizer, como se, não se preocupando em observar a palavra, mas o sentido, diz: "É a melhor coisa do mundo, deste-me a vida." ${ }^{7}$ (p. 273-4)

7 “[...] si uno traduce aquello de Terencio Idne estis auctores mihi? no queriendo apartarse de la letra, habrá de decir ¿De esto me sois autores? y así no se entenderá lo que el poeta quiso decir, pero, si, escribiendo de su cabeza, querrá decir aquella misma sentencia dirá: ¿Esto me aconsejáis a mí?, y es lo mismo que sintió el poeta, aunque se dice por otras palabras. Y de la misma manera, si otro querrá poner en romance aquello mismo de Terencio: $O$ factum bene, beasti me, dice: ¡Oh cómo está hecho bien! me has hecho bien aventurado, no hablará el propio castellano, ni exprimirá tan bien lo que el poeta quiso decir como si, no curando de mirar a la palabra, sino al sentido, dice: Está lo mejor del mundo, me has dado la vida.” 


\section{LITERÁRIA DAS LÍNGUAS NEOLATINAS}

Tanto “falar o castelhano próprio" (respeitar as propriedades da língua de chegada) quanto "exprimir o que o poeta quis dizer" (fidelidade à expressão do autor) eram princípios dos quais não se poderia abrir mão na tradução renascentista, por isso ela era vista como uma tarefa árdua. A tradução ideal era aquela que conseguia exprimir perfeitamente o sentido sem negligenciar, porém, nenhum aspecto formal, o que exigia grande conhecimento e habilidade, por causa das diferenças entre as línguas. Mas, o fato de não haver correspondência entre as propriedades das línguas não significava que uma não pudesse expressar o que estava dito noutra. Para os renascentistas, todas as línguas tinham as mesmas potencialidades, cabendo aos usuários de cada uma desenvolvê-la. Por isso, muitas vezes, diante de uma dificuldade tradutória, a opção mais viável era seguir o estilo do autor, explorando então os recursos existentes na língua de chegada. A partir do exercício com as diferentes línguas, em que o tradutor tinha de buscar soluções criativas, os vernáculos foram reelaborados. Como revela Peletier (1555; MARASCHIN, 2015), diante da diferença morfossintática do vernáculo em relação ao latim, em que não se podia contar com o sistema de casos e declinações, seria preciso encontrar, ou inventar, outros meios de obter o mesmo efeito expressivo:

[...] para nos igualarmos aos antigos, falta-nos usar todas as invenções convenientes que pudermos, enquanto a nossa língua está em nossas mãos, e em nosso poder, visto que temos outras grandes desvantagens: entre outras, que os nossos nomes não se declinam no final; outro ponto que temos em grande sujeição é que nossas palavras não se podem prepor, entremear e pospor tão livremente como no latim e no grego. Pois, se, por exemplo, eu tivesse de transladar o primeiro verso do quarto canto da Eneida, At Regina graui jamdudum saucia cura, não poderia dizer palavra por palavra, 'mas a rainha por grande há muito ferida inquietação', em vez de 'mas a rainha ferida há muito por grande inquietação’. E quem quisesse tentar remediar tal defeito, faria um grande exercício [...]8. (p. 412-3)

A tradução pela sentença era sempre preferida à palavra por palavra, levando-se em conta, além do sentido, também a adequação dos elementos gramaticais e, especialmente, a sonoridade. Era necessário que o tradutor fosse, antes de tudo, um grande estudioso dos textos clássicos, a fim de captar todos os detalhes da composição, para que, quando trouxesse a obra ao seu vernáculo, soubesse reconstruí-la com todas as suas virtudes artísticas. Toscanella (1575; MARASCHIN, 2015), para o qual traduzir bem é tomar fielmente tanto as ideias quanto as palavras do texto de partida, recomenda que seja dada atenção a todos os aspectos da forma, em especial às propriedades das palavras, de modo a conservar, entre outros valores, a sonoridade das sentenças:

8 “[...] pour nous égaler aux anciens, faudra user de toutes les inventions honnêtes que nous pourrons, tandis que notre langue est entre nos mains, et en notre gouvernement, vu même que nous avons d'autres désavantages assez: entre autres, que nos noms ne se déclinent point puis, un autre point qui nous tient en grande sujétion, c'est que nos mots ne se peuvent préposer, entremèler et postposer ainsi librement, comme en latin et en grec. Car si, par exemple, j’avois à translater le premier vers du quatrième de l'Enéide, At Regina graui jamdudum saucia cura, je ne pourrois pas dire mot pour mot, mais la Reine de grieve pieça navrée cure au lieu de, mais la Reine pieça navrée d'une grieve cure. Et qui voudroit essayer à remédier à un tel défaut, çe feroit un grand point”. 
Se as palavras do autor que se toma para verter em língua vulgar são claras, ilustres, graciosas, doces, duras, cadentes, sóbrias, altas, ásperas, e enfim de outra maneira, o bom intérprete será obrigado a escolhê-las, traduzindo com ásperas, altas, sóbrias, cadentes, duras, doces, graciosas, soantes, ilustres, claras, e de outra maneira; e a responder a todas de uma em uma, segundo a sua qualidade, [...]. É preciso observar aquelas de mais sílabas e menos sílabas e, se for possível, encontrar uma palavra da mesma quantidade de sílabas; como se lucidus fosse traduzido dizendo lúcido e não claro; porque lúcido tem três sílabas, como tem o nome latino lúcido; [...]. E há que se observar ainda a duração e brevidade, [...] se como no som dos instrumentos o tempo importa infinitamente e, se não se soasse a tempo, a harmonia tornar-se-ia desagradável, assim, não observando o tempo que trazem consigo as sílabas longas e breves, o som que resulta da tradução é inteiramente desagradável, ou pouco agradável. ${ }^{9}$ (p. 551-2)

Seu rigor aplicado à ordem das palavras na tradução não supera, porém, a importância que ele dá ao uso do ouvido, que era o "juiz" dos letrados renascentistas:

[...] tenho por certo que o tradutor, traduzindo, seja obrigado a colocar o verbo vernáculo onde está o latino; o nome onde está o nome, o pronome onde está o pronome; e assim todas as outras partes da oração, a menos que perceba que o som tenha ficado muito ruim, e o número, pois então fará bem em interpor, ou pospor, ou por antes aquela palavra que saberá trazer mais ornamento e graça à tradução. $^{10}$ (Id., p. 553, grifo nosso)

A atividade tradutória, dessa maneira, desenvolve a sensibilidade artística, contribuindo para a formação dos novos poetas, que assim aprendem a descobrir, ou criar, os valores expressivos do vernáculo. Pela experiência do traduzir, exercitando o ouvido e buscando a harmonia e adequação das palavras nas sentenças, o letrado renascentista aprimora o gosto pela composição bem elaborada, que depois vai ajudar a definir a "bela" língua, a que se vai priorizar na escrita literária. Os tradutores renascentistas assumiam com responsabilidade a tarefa de zelar pelas qualidades da língua escrita da sua comunidade, buscando melhorá-la cada vez mais, cientes de que estavam atuando em benefício de seus usuários. A tradução “correta”, que devia recuperar tanto o sentido quanto os aspectos formais $^{11}$, era, para eles, um sinal de que a cultura receptora, com sua língua

9 “[...] Se le parole dello autore, che l'huomo prende a volgere in lingua volgare, saranno chiare, illustri, vaghe, dolci, dure, cadenti, gravi, alte, aspre, e in fine d'altra maniera, sarà constretto il buono interprete a sceglierne traducendo d'aspre, d'alte, gravi, cadenti, dure, dolci, vaghe, sonanti, illustri, chiare, e d'altra maniera; e a rispondere a tutte d'una in una secondo la loro qualità, [...]. Bisogna osservare quelle di più sillabe, e manco sillabe, e se possibile è trovare una parola della medesima quantità de sillabe; come se si traducesse lucidus, dire lucido, e non chiaro; perché lucido ha 3 sillabe, come ha il nome latino lucido; [...] e di più si ha avvertire alla loro lunghezza, e brevità, [...] , si come nel suono de gl'instrumenti importa infinitamente il tempo, e se non si sonasse a tempo, l'harmonia riuscirebbe ingrata, così non servando il tempo, che portano con loro le sillabe lunghe e brevi, il suono della traduttione riesce è del tutto ingrato, o poco grato”.

10 “[...] tengo per certo che il traduttore sia obligato a porre il verbo volgare, traducendo, dove è il latino, il nome dove è il nome, il pronome dove è il pronome, e così tutte le altre parti dell'oratione, se già non vedesse che fosse troppo cattivo suono, e numero, che allhora poi farà bene a interporre, 0 posporre, o porre dinanzi quella voce che conoscerà apportare più d'ornamento e di vaghezza alla tradottione.”

11 Conforme os princípios sistematizados por Bruni (1420-6; FURLAN, 2011), no De interpretatione recta. 


\section{LITERÁRIA DAS LÍNGUAS NEOLATINAS}

literária já formada, havia conquistado um novo status e não ficava em débito com as ideias do texto-fonte.

Nos textos da época, algumas vezes, a referência à tradução aparece de forma indireta, por meio de expressões em que o original "fala" na língua receptora, demonstrando-se, de qualquer modo, que esta já tem condições de dar voz ao outro, tão bem quanto a língua de partida, seja ela clássica ou moderna. O personagem Peretto, em Speroni (1542; MARASCHIN, 2015), defendendo a utilidade das traduções, diz que as artes e as ciências agora "estão nas mãos dos latinos e dos gregos; mas devemos fazer com que no futuro todas as línguas possam falar de todas as coisas por todo o mundo." 12 (p. 466); Du Bellay (1549; MARASCHIN, 2015, p. 353), sobre as traduções de textos de ciências, diz que através delas "gregos e latinos aprenderam a falar francês [...] por muitas e excelentes penas do nosso tempo" "13; Morales (1586; MARASCHIN, 2015, p. 332) destaca que "a história romana e muito da antiguidade latina e grega já falam o castelhano elegantemente e com propriedade e polidez"14, e também que "o Cortesão não fala melhor na Itália, onde nasceu, do que na Espanha, onde Boscán mostrou-o extremamente bem." ${ }^{\prime 15}$ (p. 333)

Tanto quanto a escolha das palavras ao compor um texto, também era relevante para eles escolher bons autores e obras bem elaboradas, porque isso, além de confirmar a habilidade artística do tradutor, tornaria o vernáculo honrado, pela comprovação da sua capacidade de receber toda a arte do texto de partida. Portanto, outro requisito importante da atividade tradutória renascentista, além do modo de traduzir respeitando ao máximo todos os valores do original e recriando-o na língua receptora, era a seleção das obras, cuja preferência era dada às dos melhores autores da Antiguidade, modelos inquestionáveis. Por isso, Damião de Góis refere-se à importância de traduzir os grandes filósofos em vez de compor coisas novas com suas ideias "sem artifício retórico, nem dialético", como faziam as "pessoas cobiçosas de glória” (GÓIS, 1538; MARASCHIN, 2015, p. 560). Se era possível à nova língua expressar bem as ideias dos grandes clássicos, confirmava-se que ela já estava apta, formada e pronta para ser igualada às demais, ou até superá-las. Caso ainda lhe faltasse algum elemento, essa lacuna poderia ser preenchida através de ações enriquecedoras dos letrados, sempre tomando como referência os livros dos autores exemplares, considerados "bem escritos”, em grego e/ou em latim.

A tradução renascentista reelabora as novas línguas literárias em todos os seus aspectos constitutivos. Pois, para realizar uma tradução considerada "boa" conforme os preceitos da época, era preciso que o tradutor possuísse o domínio completo dos elementos de ambas as línguas, além de, muitas vezes, ter de dotar a língua receptora de todos os recursos necessários à expressão artística. A tarefa do tradutor, então, reveste-se de uma série de conhecimentos formais, uma vez que não basta saber fazer a transposição do sentido para que os clássicos possam "falar bem” em vernáculo, mas é preciso dar-lhe condições, para que se possa elogiar a sua capacidade de recepção das ideias de maneira adequada. É através deste

12 “[...] nelle mani de’ latini e de’ greci; ma sì fare debbiamo per l’avenire, che d’ogni cosa per tutto

'l mondo possa parlare ogni lingua.”

13 "grecs et latins, ont appris à parler français [...] par maintes excellentes plumes de notre temps."

14 "La Historia Romana, y mucho de la antigüedad latina y griega hablan ya hermosamente, y con propiedad y limpieza el castellano”.

15 "El cortesano no habla mejor en Italia donde nasció, que en España, donde lo mostró Boscán por extremo bien.” 
trabalho atencioso do letrado que cada língua, considerada igual a todas as outras por natureza, vai ter seu valor artístico ampliado.

Para distinguir uma língua da outra, tornando-a mais habilitada, os letrados serviam-se de vários recursos enriquecedores, desde a imitação e tradução dos clássicos, passando pela agregação de vocábulos regionais e estrangeiros, até a criação de termos novos, com grande cuidado na sua colocação. Somente a profusão de palavras não bastava para tornar a língua copiosa, era preciso também dar atenção à organização sintática, já que os vernáculos não possuíam o sistema de declinações. Por isso Peletier (1555; MARASCHIN, 2015), admitindo que havia tal lacuna no francês, propõe como solução apelar para os recursos próprios da sua língua, usando “todas as invenções convenientes” (p. 412). Pelos modelos clássicos, não apenas imitando-os, mas observando-os com discernimento, o tradutor poderia extrair os elementos necessários para a sua arte, tornando-se então criador, inovador, como ele aconselha, referindo-se ao ofício do poeta:

Que ele olhe o que é que foi feito; e se não foi feito, em quem está a falta. Note as generalidades e as particularidades; examine as passagens de filosofia, o modo de narrar, e como são diferentes a seriedade, a graça e a decência. Se houver defeitos, que os evite, coisa fácil; as virtudes, que as iguale, coisa possível; ou que as supere, coisa honrosa. ${ }^{16}$ (Id., p. 390)

Também Boscan (1543; MARASCHIN, 2015), ao explicar como havia introduzido a nova métrica na poesia da Espanha, diz ter-se ocupado longamente em perscrutar as composições utilizadas até então, para ter seu “juízo mais aberto" e, finalmente, poder consagrar na língua castelhana o verso decassílabo, no qual

[...] vemos, onde quer que se nos mostre, uma disposição muito capaz para receber qualquer matéria: grave ou sutil, dificultosa ou fácil, e igualmente para se juntar com qualquer estilo dos que achamos entre os autores antigos aprovados. $^{17}$ (p. 306)

A partir dos exercícios tradutórios com base nos princípios gramáticoretóricos, além do léxico, também a sintaxe própria das línguas neolatinas começou a ser aperfeiçoada. É num jogo de tradução que Valdés (1535; MARASCHIN, 2015) mostra aos aprendizes que não são as palavras que fazem a língua; elas não precisam ser alteradas, na passagem do latim para o castelhano, para que ocorra diferença, pois, segundo demonstra, a verdadeira diferença entre as línguas está no modo como as palavras são combinadas para formar uma sentença:

VALDÉS: [...] tomai alguns versos latinos e observai como, palavra por palavra, vo-los mostrarei quase todos castelhanos.

MÁRCIO: Tomo o início da Arte poética, de Horácio.

VALDÉS: Está bem. Humano capiti ceruicem pictor equinam/ iungere si uelit et uarias inducere plumas.

16 “Qu’il regarde qui c'est qui l'a encore fait; et s'il n'a été fait, en quoi est la faute. Avise les généralités et les particularités; examine les passages de philosophie, la façon de narrer, et combien diverse: que la gravité, que la grâce et bienséance. S'il y a des vices, qu'il les évite, chose facile: les vertus, qu'il les égale, chose possible ou les surmonte, chose honorable.”

17 “[...] vemos, dondequiera que se nos muestra, una disposición muy capaz para recebir cualquier materia: o grave o sotil, o dificultosa o fácil, y asimismo para ayuntarse con cualquier estilo de los que hallamos entre los authores antiguos aprovados.” 


\title{
LITERÁRIA DAS LÍNGUAS NEOLATINAS
}

\begin{abstract}
VALDÉS: Agora escutai-os, palavra por palavra: Humana cabeça cerviz pintor de égua ajuntar se quiser e várias colocar penas.

CORIOLANO: Para mim esta é uma algaravia muito cerrada.

VALDÉS: Tendes razão, porque está dito palavra por palavra, mas com as mesmas palavras, colocando cada uma delas em seu lugar, entendereis.

CORIOLANO: Então, colocai-as.

VALDÉS: Se a uma cabeça humana quiser um pintor juntar uma cerviz de égua e colocar-lhe várias penas, etc. Entendeis agora?

CORIOLANO: Sim, e muito bem.

VALDÉS: Pois acredito que também vedes como, nestes dois versos, não achais quase nenhum vocábulo que não conheçais por latino, a não ser o quiser. ${ }^{18}$ (p. 289)
\end{abstract}

Entre os renascentistas, embora nem sempre a tradução seja reconhecida como um meio útil na promoção do vernáculo, há uma constante afirmação dos requisitos necessários para obtê-la de acordo com os preceitos comuns naquela época. Até mesmo Du Bellay (1549; MARASCHIN, 2015, p. 355), que considerava a tradução uma "traição", por não dar conta dos valores artísticos do original, fornece dados sobre os preceitos tradutórios comuns à sua época, tais como a importância da eloquência (palavras apropriadas e pertencentes ao uso comum, recurso a figuras e ornamentos), sem a qual "toda oração e poema são nus, mancos e débeis”; a proprietas, “cada língua tem um não sei quê, próprio somente dela” e, principalmente, sobre "a lei de traduzir”, que é "não se afastar dos limites do autor”, trazendo as coisas da língua de partida "com a mesma graça e naturalidade”. Também Valdés (1535; MARASCHIN, 2015), embora não valorize a tradução como atividade enriquecedora do vernáculo, conhece e aplica os preceitos da tradução renascentista (elocutiva), ao julgar obras traduzidas. Por exemplo, ele considera que o Enquiridion de Erasmo foi bem traduzido em castelhano por Arcidiano del Alcor porque "pode competir com o latino, quanto ao estilo" (p. 272), o que significa que o tradutor conseguiu encontrar meios de reproduzir a arte do original na língua de chegada, vencendo a dificuldade imposta pelas propriedades linguísticas. João de Barros, por sua vez, ressalta que, enquanto as outras línguas românicas enriqueciam seu léxico pela escrita, através das "trasladações latinas”, a língua portuguesa se expandia tomando os vocábulos estrangeiros diretamente pelo contato ao vivo com outros povos, não dispensando, porém, a preocupação com a sonoridade do seu vernáculo, ao "usar d'alguns termos latinos que a orelha bem receba, porque ela julga a linguagem e música, e é censor de ambas” (BARROS, 1540; MARASCHIN, 2015, p. 565).

18 “VALDÉS: [...] tomad algunos versos latinos y mirad cómo, palabra por palabra, os los mostraré casi todos castellanos./ MARCIO: Tomo el principio del Arte poética, de Horacio./ VALDÉS: Bien está. Humano capiti cervicem pictor equinam/ iungere si velit et varias inducere plumas./MARCIO: Abastan esos./ VALDÉS: Ahora escuchadlos, palabra por palabra: Humana cabeça cerviz pintor de yegua ayuntar si querrá y varias poner plumas./ CORIOLANO: Para mí es esa una muy cerrada algarabía./ VALDÉS: Tenéis razón, porque va dicho palabra por palabra, pero con las mismas palabras, poniendo cada una de ellas en su lugar, lo entenderéis./ CORIOLANO: Ea, ponedlas./ VALDÉS: Si a una cabeça humana querrá un pintor ayuntar una cerviz de yegua y ponerle varias plumas, etc. ¿Lo entendéis ahora?/ CORIOLANO: Sí, y muy bien./ VALDÉS: Pues vos también creo que veis cómo en estos dos versos no halláis vocablo ninguno que no lo conozcáis casi por latino, si no es el querrá.” 


\section{Considerações finais}

A ascensão literária dos vernáculos ao nível das línguas clássicas, que começa no século XVI, tem uma relação importante com a atividade tradutória. A tradução renascentista, ao se tornar uma "retextualização fundamentada na retórica elocutiva” (FURLAN, 2002), caracteriza-se como uma atividade renovadora da língua de chegada, influenciando, assim, a formação culta daquelas línguas modernas nas quais quanto mais se traduzia mais imponentes se tornavam. Sem essa formação, elas não teriam meios de superar a condição de "bárbaras" e "pobres" a que alguns literatos haviam relegado-as, por causa da sua incompatibilidade com a expressão de todos os valores estéticos das obras clássicas, que até então, como já nos referimos, eram vulgarizadas, mas não traduzidas com toda a sua arte.

Por meio da tradução, com base na concepção retórica da linguagem e selecionando as obras tidas como "bem escritas", os renascentistas aprimoraram as literaturas e promoveram muitas línguas vernáculas. Diversas traduções, realizadas nas línguas neolatinas aqui citadas, como Idílios de Teócrito por Annibale Caro, em italiano, Vidas paralelas de Plutarco por Amyot, em francês, Bucólicas de Virgílio por Fray Luis de León e Metamorfoses de Ovídio por Pedro Sánchez de Viana, em espanhol, constituem exemplos de que os princípios da elocutio consagraram um novo modo de os letrados também escreverem seus próprios textos nessas línguas. Com esse novo modo, aliado aos acontecimentos de ordem cultural, social, política e econômica, essas línguas, dentre as quais o português. passaram a ser reconhecidas como capazes de expressão artística, historicização, produção e transmissão de conhecimentos, enfim, consideradas aptas a expressar os valores culturais dos grupos que representavam.

Pela experiência do "traduzir bem", que, na concepção renascentista, envolve requisitos como o conhecimento amplo das línguas, das culturas, dos princípios gramático-retóricos e das possibilidades expressivas, os literatos desenvolvem a habilidade de "inventar bem", ao escreverem textos na sua própria língua, favorecendo, a partir do Renascimento, a composição de grandes obras da literatura ocidental, em vários gêneros clássicos, com o objetivo de proporcionar prazer estético (HIGHET, 1954). Essa é uma característica renascentista, em que a obra literária, mesmo em prosa, proporciona deleite ao ouvido.

Leila Maraschin

leilamaraschin@gmail.com

$\operatorname{Prof}^{a} \mathrm{Dr}^{a}$, Universidade Federal de Santa Maria 


\section{Referências bibliográficas}

BARRos, João de. Diálogo em louvor da nossa linguagem (1540). Grammatica da lingua portuguesa. Olyssippone: Apud Lodouicum Rotorigiu Typographum, MDXL, p. 50-61.

BAssnett, Susan. Estudos de Tradução. Trad. Sônia Terezinha Gehring et al. Porto Alegre: Editora da UFRGS, 2005

Bembo, Pietro [1525]. Prose della volgar lingua, Gli Asolani, Rime, a cura di Carlo Dionisotti. Torino Utet, 1966. (Letteratura italiana Einaudi).

Boscán, Juan. A la duquesa de Soma (1543). Obras poéticas. Libro II. Ed. de Enrique Canedo. Madrid: Calleja, 1917. Disponível em: <http://www. cervantesvirtual.com/nd/ark:/59851/bmcq8172>. Acesso em: 13 fev. 2015.

BRUNI, Leonardo; FURLAN, Mauri. De interpretatione recta (1420-6))/Da tradução correta. In: Scientia Traductionis $\mathrm{n}^{\circ}$ 10. Florianópolis: PGET, 2011. p. 1647. Disponível em: http://dx.doi.org/10.5007/1980-4237.2011n10p16. Acesso em: 11 jul. 2015.

Burke, Peter. O Renascimento italiano: cultura e sociedade na Itália. Tradução de José Rubens Siqueira. São Paulo: Nova Alexandria, 2010(b).

Du Bellay, Joachim. La défense et illustration de la langue française (1549). Paris: Nelson, 1936. [complété par l'édition Louis Humbert chez Garnier]. Disponível em: <http://www.axl.cefan.ulaval.ca/francophonie/du_bellay. htm>. Acesso em: 11 de março de 2015.

FolenA, Gianfranco. Volgarizzare e tradurre. Torino: Einaudi, 1994.

FurLAN, Mauri. La retórica de la traducción en el Renacimiento. Elementos para la constitución de una teoría de la traducción renacentista. Barcelona: Universitat de Barcelona, 2002. (Tese de Doutorado) Disponível em: $<$ http://www.pget.ufsc.br/publicacoes/professores.php?autor=9>. Acesso em: 17 de janeiro de 2011.

GeLli, Giovan Battista. Ragionamento (1551). Opere di Giovan Batista Gelli, a cura di Agenore Gelli. Firenze: Felice Le Monnier, 1855.

Goes, Damián de [1538]. Carta dedicatoria. In: Livro de Marco Tullio Ciceram, chamado Catam Mayor ou da Velhica (sic), dedicado á Tito Pomponio Attico. Lisboa: Typographia Rollandiana, 1545 [reimpressa em 1845]. Disponível em: http://www.larramendi.es/menendezpelayo/i18n/corpus/ unidad.cmd?idUnidad=100831\&idCorpus=1000. Acesso em: 05 de novembro de 2015.

Highet, Gilbert. La tradicion Clasica. Influencias griegas y romanas em la literatura occidental. Traducción de Antonio Alatorre. 2 v. México-Buenos Aires: Fondo de Cultura Economica, 1954.

KRISTELLER, Paul Oskar. El pensamiento renascentista y sus fuentes. Traducción de Federico Patán López. México: Fondo de cultura económica, 1993.

LAusBerg, Henrich. Elementos de retórica literária. Tradução de R. M. Rosado Fernandes. 2. ed. Lisboa: Fundação Calouste Gulbenkian, 1972.

Micó, José María. La época del Renacimiento y del Barroco. In: LAFARGA, F.; Pegenaute, L. (Org.). Historia de la Traducción en España. Salamanca: Ambos Mundos, 2004. p. 174-207 
Morales, Ambrosio de. Discurso sobre la lengua castellana [1586]. Las obras del maestro Fernan Perez de Oliva: con otras cosas que van añadidas. Cordova: Gabriel Ramos Bejarano, 1586.

Peletier du MAns, Jacques. L'art poetique departi au deux livres. Lyon: Jan de Tournes, 1555./ Art Poétique I. Les bibliothéques françoises de La Croix du Maine et de du Verdier sieur de Vauprivas. Volume 4. Paris: Saillant \& Nyon, 1773, p. 292-300.

SPERONI, Sperone. Dialogo delle lingue [1542]. Curatore: Mario Pozzi. Edizione Elettronica, 2001. Disponível em: <http://www.liberliber.it/biblioteca/ licenze/>. Acesso em 18 de fevereiro de 2014.

Toscanella, Orazio. Discorso del tradurre. Discorsi cinque. Venetia: Apresso Pietro de' Franceschi \& Nepoti, 1575. p. 28-35.

VALDÉs, Juan de. Diálogo de la lengua (1535). Ed. Modern. de E. Boehmer (1895). Madrid: $\quad$ Espasa-Calpe, $1976 . \quad$ Disponível em: http://www.cervantesvirtual.com/obra-visor/dialogo-de-la-lengua--0/html/ fede437e-82b1-11df-acc7-002185ce6064_2.html\#I_0_. Acesso em: 15 de março de 2014. 